\title{
Antibody-Targeted Nanoparticles for Cancer Treatment
}

Thomas Carter ${ }^{1}$, Paul Mulholland ${ }^{1,2}$, Kerry Chester $^{1}$

\section{Abstract}

Nanoparticles are diverse and versatile with physical properties that can be employed for use in cancer medicine. Targeting nanoparticles using antibodies and antibody fragments could overcome some of the limitations seen with current targeted therapies. This review will discuss the role of antibody-targeted nanoparticles in the treatment of cancer: as delivery vehicles, targeted theranostic agents and in the evolving field of cancer hyperthermia.

\section{Keywords: Antibodies, nanoparticles, targeting, cancer treatment, clinical translation, theranostics, hyperthermia}

\subsection{Introduction}

As our understanding of cancer biology has evolved, so too has the appreciation that antibody targeted cancer treatment offers significant advantages over conventional therapy. A number of strategies have been successful in the clinic: most notably the use of monoclonal antibodies (mAbs) to target cancer-specific antigens [1], deliver cytotoxic chemotherapy in the form of antibody-drug conjugates (ADCs) [2], release brakes on the immune system [3] and to recruit cytotoxic T cells [4]. However, the successes of these targeted therapies are not without drawbacks, including dose-limiting toxicities.

Advances in nanotechnology have enabled the creation of a vast array of devices, collectively referred to as nanoparticles (NPs), which possess unique physical, chemical and biological properties. The use of antibodies to target these nanosized drug delivery vehicles offers new potential that can be harnessed for use in cancer medicine [5]. Indeed, a small number of targeted NPs have been already been successfully translated into early phase clinical trials using targeting ligands [6-8]. Antibodies (Abs) have become the most widely studied of these targeting ligands [9], due to their high specificity and the vital role they play in modern cancer therapeutics. 
The main challenge for Ab-targeted NPs is ensuring that as well as demonstrating efficacy the NP has an adequate plasma half-life and can specifically target cancer cells with a tolerable side effect profile. There are controversies over which NP platforms can best offer these properties, with unanswered questions concerning cellular interaction and uptake, potential toxicities and how NP properties affect behaviour both in-vitro and in-vivo [10]. A robust understanding of the physical properties of NPs is required to guide research into the cellular and physiological interactions of NPs, generating clinical-grade products that could become the next generation of cancer treatments.

This review aims to define and outline the different NP platforms that are currently used in pre-clinical and translational cancer medicine and the challenges faced in the Ab-functionalisation of NPs. Research regarding the various approaches and advantages offered by Ab-targeted NPs in cancer therapy will also be discussed.

\subsection{Nanoparticles}

NPs are defined by the Commission of the European Union as any naturally occurring or manufactured particulate material either unbound, as an aggregate or agglomerate, where at least half of the particles have one or more external dimensions between 1 and 100nm in size [11]. However, there remains no formal consensus on the definition [12] and whilst NPs are often defined by their size it is generally considered important to also define them by properties not shared with other particles with the same chemical composition [13]. For example high mobility in the free state, large surface area to volume ratio and, in some cases, the nanosize-dependent exhibition of quantum effects which control physical properties and NP behaviour [14].

This wide and diverse range of functional properties is facilitated by the variety of materials available to synthesise NPs. The resulting versatility offers attractive translational potential for a number of biomedical applications such as targeted 
delivery of treatment, innovative imaging techniques and novel therapeutics for hyperthermia. Table 1 shows the favourable physical characteristics of the NP treatment platforms discussed in this review. Given these characteristics, it is not surprising that over the last decade nanoparticles have received increasing attention for their exciting potential in both the diagnosis and treatment of cancer. 


\begin{tabular}{|c|c|c|}
\hline Nanoparticle & Size & Favourable Physical Characteristics \\
\hline \multicolumn{3}{|c|}{ NATURAL POLYMERS* (Albumin) } \\
\hline [15] & $50-30$ & $\begin{array}{l}\text { Biocompatible, biodegradable, non-toxic and non-immunogenic. } \\
\text { Straightforward to cross-link and chemically modify, drugs } \\
\text { readily incorporated into albumin polymer matrix. }\end{array}$ \\
\hline \multicolumn{3}{|c|}{ SYNTHETIC POLYMERS* (Poly-lacticoglycolic acid (PLGA) } \\
\hline [16] & $50-300 \mathrm{~nm}$ & $\begin{array}{l}\text { FDA approved synthetic material that is non-toxic and undergoes } \\
\text { hydrolysis in-vivo to produce biodegradable metabolites. Drugs } \\
\text { easily incorporated into the matrix. }\end{array}$ \\
\hline \multicolumn{3}{|l|}{ LIPOSOMES* } \\
\hline [17] & $20-1000 \mathrm{~nm}$ & $\begin{array}{l}\text { Well established as cancer therapeutics, can encapsulate } \\
\text { hydrophilic and lipophillic drugs, soluble, low uptake by } \\
\text { macrophages, favourable stability in-vivo, and as colloids, protect } \\
\text { drugs from breakdown. }\end{array}$ \\
\hline \multicolumn{3}{|l|}{ MICELLES* } \\
\hline [18] & & $\begin{array}{l}\text { Unique core-shell architecture, hydrophobic core acts as natural } \\
\text { carrier environment, hydrophilic shell enables stability in } \\
\text { aqueous solution, structural modifications can further augment } \\
\text { tumour cell uptake }\end{array}$ \\
\hline \multicolumn{3}{|l|}{ DENDRIMERS* } \\
\hline$[19,20]$ & & $\begin{array}{l}\text { Symmetrical branched polymeric macromolecules with a central } \\
\text { core allow either encapsulation or conjugation of therapeutic } \\
\text { agent. Self-assembling, polyvalent, chemically stable, non-toxic } \\
\text { and soluble. }\end{array}$ \\
\hline \multicolumn{3}{|c|}{ IRON-OXIDE NANOPARTICLES* (Superparamagnetic iron-oxide nanoparticles (SPIONs)) } \\
\hline [21] & $10-100 \mathrm{~nm}$ & $\begin{array}{l}\text { Biocompatible and biodegradable, established clinical use as } \\
\text { magnetic resonance imaging (MRI) contrast agents, controllable } \\
\text { by an externally applied magnetic field, diverse formulations } \\
\text { allow fine-tuning of physicochemical properties }\end{array}$ \\
\hline \multicolumn{3}{|c|}{ SILICA (Porous Silica Nanoparticles (pSiNPs)) } \\
\hline [22] & & $\begin{array}{l}\text { Good chemical and thermal stability, large surface area and pore } \\
\text { volume. Can encapsulate large amounts of bioactive molecule and } \\
\text { promote controlled drug release. Also offers simple surface } \\
\text { functionalisation }\end{array}$ \\
\hline \multicolumn{3}{|c|}{ GOLD NANOPARTICLES* (Gold nanoparticles (AuNPs), Gold nanorods) } \\
\hline [23] & $1-100 \mathrm{~nm}$ & $\begin{array}{l}\text { Intense light absorption and high photothermal conversion rate, } \\
\text { and ease of synthesis in a variety of shapes and sizes. Good } \\
\text { biocompatibility, colloidal stability and simple ligand conjugation } \\
\text { chemistry. }\end{array}$ \\
\hline \multicolumn{3}{|c|}{ CARBON NANOPARTICLES (Carbon nanotubes (CNTs)) } \\
\hline [24] & $1-10 \mathrm{~nm}$ & $\begin{array}{l}\text { High carrying capacity, and high propensity to traverse cell } \\
\text { membranes } \\
\text { Easily chemically modified or functionalized through formation } \\
\text { of stable covalent bonds. }\end{array}$ \\
\hline \multicolumn{3}{|c|}{ QUANTUM DOTS (QDs) } \\
\hline [25] & $2-10 \mathrm{~nm}$ & $\begin{array}{l}\text { Broad absorption spectra and high fluorescence quantum yield, } \\
\text { high photostability. Possibility of multiplexing (different colours } \\
\text { of QDs used within one assay with a single excitation source). Can } \\
\text { be combined with other NP platforms for cancer theranostics. }\end{array}$ \\
\hline
\end{tabular}


Table 1. Physical characteristics of the commonly used NP platforms exploited for clinical applications. NPs labelled with an asterix $(*)$ have been used in the clinic for the diagnosis or treatment of cancer [26].

\subsection{Targeting Nanoparticles for Cancer Treatment}

The abnormal hyperpermeable vasculature and impaired lymphatic drainage found within tumours [27] can lead to passive accumulation of NPs within malignant tissues. This process is known as enhanced permeability and retention (EPR). EPR has been demonstrated extensively in pre-clinical research and in the clinical setting using liposomal drugs such as pegylated liposomal doxorubicin (PLD). The success of PLD lies in encapsulating the toxic anthracycline doxorubicin within $100 \mathrm{~nm}$ liposomes to limit drug uptake into sensitive healthy tissues such as the myocardium thereby avoiding the severe dose-limiting cardiotoxicity commonly seen with free doxorubicin [28]. Once localised within the tumour, liposome breakdown releases the doxorubicin, causing local tumour cell death.

Whilst EPR can increase overall tumour uptake of NPs, specific targeting of NPs to cancer cells can be best achieved through the addition of a targeting moiety [29], a number of which have shown promise including proteins, nucleic acids and small molecules (Figure 1). 


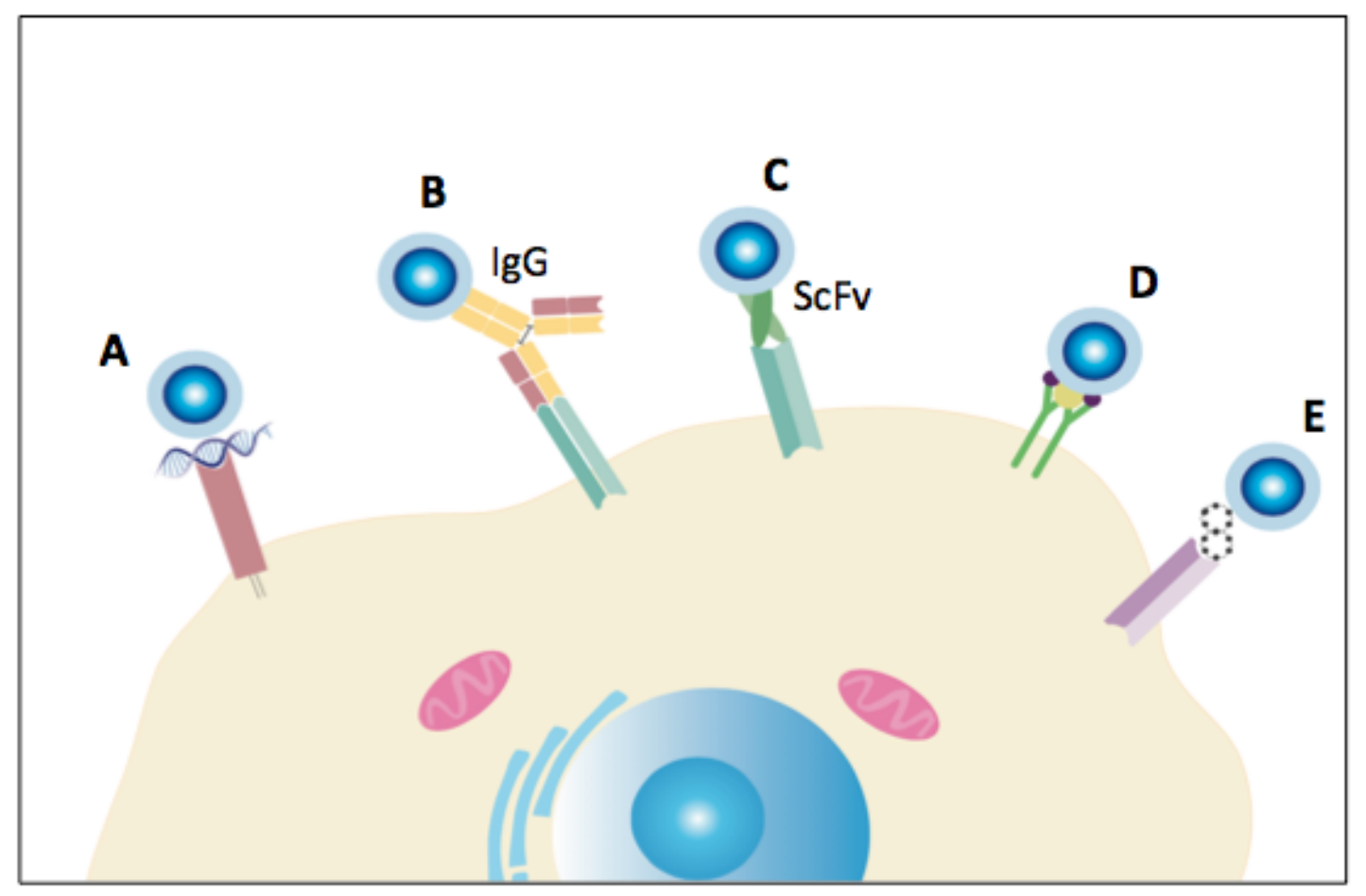

Figure 1. Schematic showing the most commonly used ligands to actively target NPs including DNA aptamers (A), antibodies; as both whole immunoglobulin G molecules (IgGs) (B) and fragments such as single chain variable fragments $(\mathrm{scFv})(\mathrm{C})$, non-immunoglobulin proteins such as transferrin (D) and small molecules such as folic acid (E). Figure adapted from [30].

Antibodies, the most widely used ligands for NP targeting, recognise a vast array of antigens, due to their unique specificity conferred by the complementarity determining regions (CDRs) (Figure 2). Antibodies can be readily generated as intact IgGs or as fragments such as single chain variable fragments (scFvs) (Figure 2) in defined, recombinant form [31, 32]. Antibody targeting appears to be complementary to passive intratumoural accumulation mediated by EPR [3335]. Ab-NPs also show improved efficacy and cytotoxicity compared with nontargeted NPs [36]. 


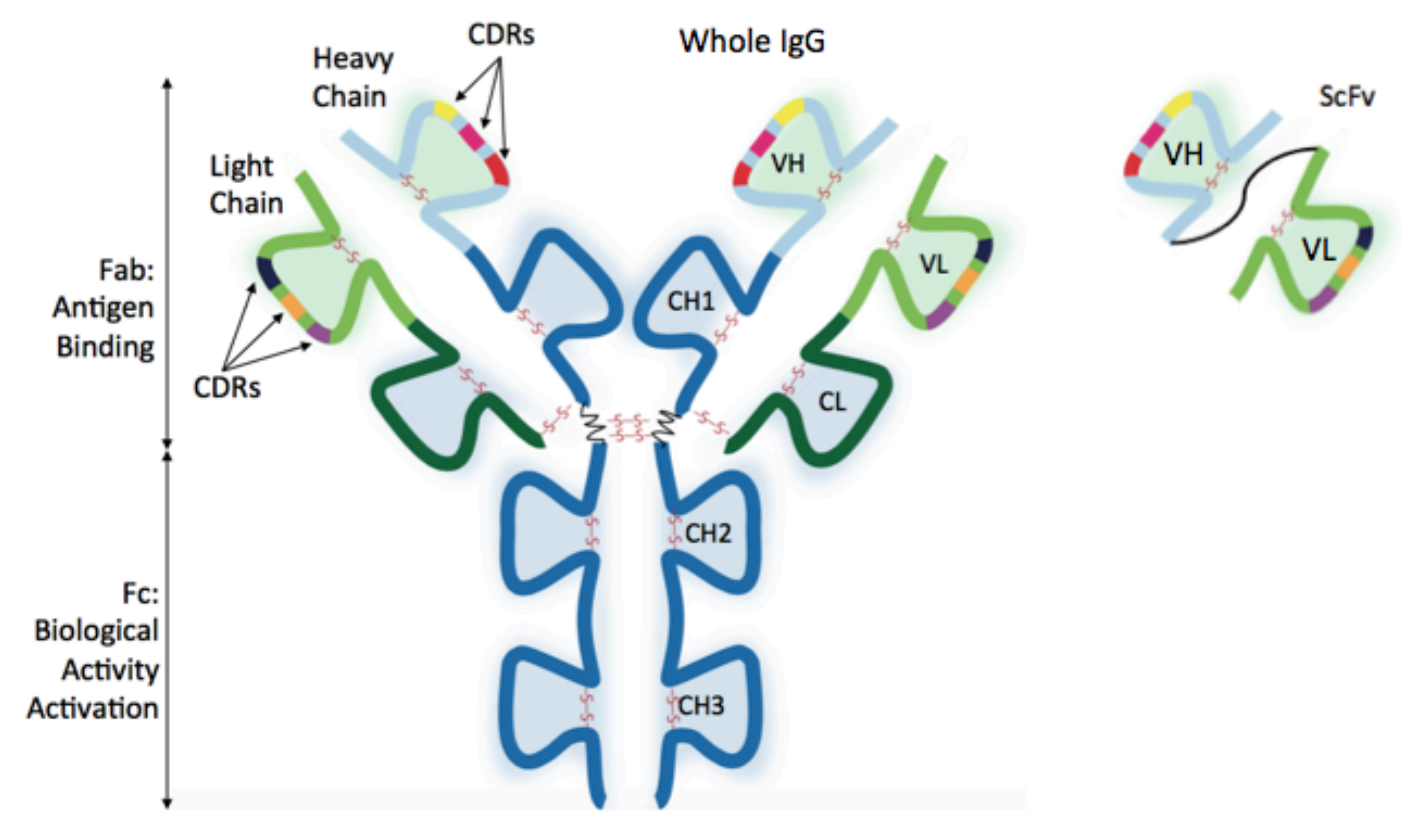

Figure 2. Immunoglobulin G (IgG) Structure: The heavy chain (blue) is made up of one variable region $(\mathrm{VH})$ and three constant regions ( $\mathrm{CH} 1, \mathrm{CH} 2, \mathrm{CH} 3)$. The light chain (green) has one variable (VL) and one constant (CL) region. On each variable chain there are three complementarity determining regions (CDRs), which bestow the vast variability in specific antigen binding capacity. VH and VL together with $\mathrm{CH} 1$ and $\mathrm{CL}$ are known as the Fab (fragment, antigen binding), and the remainder of the molecule is known as the Fc region (fragment, crystallisable), which confers biological activity and half-life. Recombinant antibody fragments include single chain variable fragments (scFvs), which are made up of the VH and VL segments joined using a peptide linker.

\subsection{Antibody-Nanoparticle bio-conjugation}

The challenges in establishing conjugation strategies that preserve the functionality of both the antibody and NP during the conjugation process can be broadly divided into three main categories; controllability, stability and reliability. Controllability relates to the number of antibodies conjugated to each NP and the orientation of this interaction, both of which can greatly affect the subsequent functional ability of an Ab-NP conjugate [37]. Whilst it remains difficult to pre-determine the number of Abs conjugated to each NP, it is possible to fractionate functionalised NPs based on the number of linker molecules on the NP surface [38]. Sophisticated techniques have also been developed to control antibody orientation [39, 40], resulting in preservation of Ab bioactivity [41]. These new techniques have been reported to achieve $\mathrm{Ab}$ bioactivity as high as $88 \%$ of the naked antibody $[41,42]$. 
It is crucially important to maintain stability of the NP and Ab throughout the conjugation process and to ensure that the final conjugate has acceptable stability in-vitro and in-vivo. Harsh reaction conditions should be avoided, as these can trigger antibody unfolding which impairs antigen binding [43]. It is also necessary that the attachment of Ab to NP surface does not lead to unfolding from unfavourable interactions of the protein side chains with the NP surface [44]. The choice of conjugation strategy has also been shown to affect long-term stability. For example, whilst the highly specific interaction between streptavidin and biotin adaptor molecules (engineered onto the nanoparticle surface and antibody respectively) successfully generate Ab-NP conjugates capable of targeting tumour cells in-vitro [45], these conjugates did not demonstrate acceptable long-term colloidal stability. However, by adding a reactive thiol group to the $\mathrm{Ab}$ and covalently cross-linking it via a bifunctional linker molecule to the nanoparticle surface higher binding efficiency and improved stability was achieved with equal in-vitro targeting efficacy [46].

Reliable, reproducible and well validated conjugation procedures are essential to enable upscale development for use in clinical applications [47] and to date, this has been most successfully achieved by direct covalent conjugation via linker molecules. Established covalent conjugation methods include carbodiimide coupling, maleimide coupling and click chemistry (copper catalysed alkyne-azide cycloaddition reactions) [48], as shown in figure 3. In the case of AuNPs goldsulphur linkage can be exploited, utilising the high affinity with which thiol modified ligands bind to gold surfaces [49]. The advantages and disadvantages of conjugation strategies are summarised in table 2 , and have been reviewed in depth by Montenegro et. al. [50]. 
A
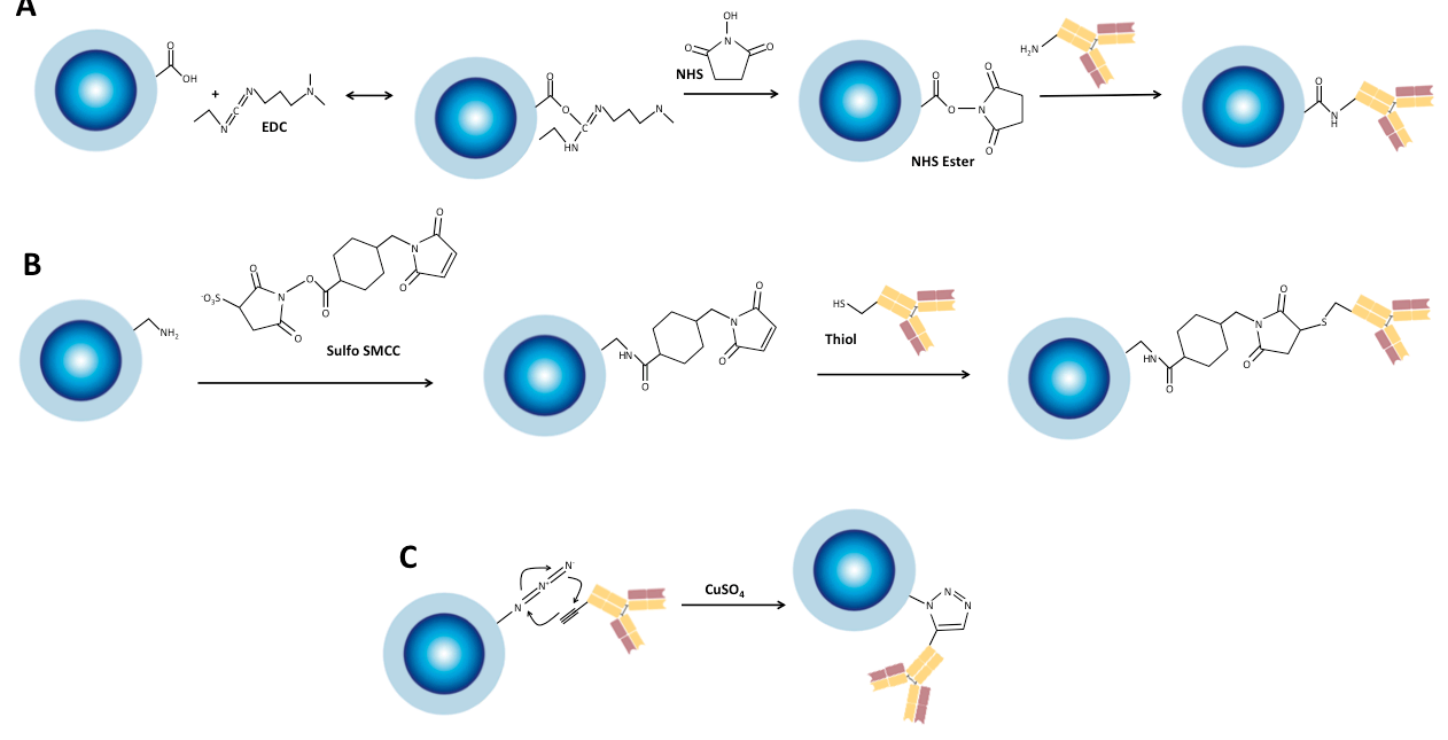

Figure 3. Established methods for the covalent conjugation of antibodies to nanoparticles: (A) carbodiimide coupling, (B) maleimide coupling and (C) Copper catalysed 'click' cycloaddition reaction [48].

\begin{tabular}{|c|c|c|}
\hline $\begin{array}{c}\text { Conjugation } \\
\text { Strategy }\end{array}$ & Advantages & Disadvantages \\
\hline $\begin{array}{l}\text { Physical Adsorption } \\
\text { (ionic, electrostatic, } \\
\text { van-der-Waals) }\end{array}$ & $\begin{array}{l}\text { - Simple and straightforward } \\
\text { - Unnecessary to modify either the } \\
\text { Ab or the NP } \\
\text { - Electrostatic attraction can } \\
\text { orientate the antibodies 'end on' } \\
\text { preserving binding ability }\end{array}$ & $\begin{array}{l}\text { - Reversible } \\
\text { - Hydrophobic interaction can cause } \\
\text { denaturation of } \mathrm{Ab} \\
\text { - Electrostatic attraction is weak and } \\
\text { pH dependent } \\
\text { - Competitive displacement by serum } \\
\text { proteins can occur }\end{array}$ \\
\hline $\begin{array}{l}\text { Covalent } \\
\text { Conjugation } \\
\text { (including via linker } \\
\text { molecules) }\end{array}$ & $\begin{array}{l}\text { - } \text { Higher stability and improved } \\
\text { reproducibility } \\
\text { - Modifications to Ab usually not } \\
\text { required } \\
\text { - Oriented binding possible } \\
\text { - Use of linker-molecule can avoid } \\
\text { hostile reaction conditions } \\
\text { - Possible to control valency }\end{array}$ & $\begin{array}{l}\text { - Reaction conditions may lead to } \\
\text { protein unfolding/reduction } \\
\text { - Conditions can affect antigen binding } \\
\text { capacity } \\
\text { - Choice of binding moieties or linker } \\
\text { can significantly affect function }\end{array}$ \\
\hline $\begin{array}{l}\text { Use of adaptor } \\
\text { molecules } \\
\text { (biotin/streptavidin) }\end{array}$ & $\begin{array}{l}\text { Usually orientated binding } \\
\text { - Can resist harsh reaction } \\
\text { conditions }\end{array}$ & $\begin{array}{l}\text { - Difficult to control valency } \\
\text { - Expensive technique } \\
\text { - Reversible attachment }\end{array}$ \\
\hline $\begin{array}{l}\text { Bispecific Antibody } \\
\text { Conjugation } \\
\text { [51] }\end{array}$ & $\begin{array}{l}\text { - No need for disruptive chemical } \\
\text { conjugation } \\
\text { - Minimal impact upon NP stability }\end{array}$ & $\begin{array}{l}\text { - Long term stability unknown } \\
\text { - Only one antigen binding site } \\
\text { available }\end{array}$ \\
\hline
\end{tabular}

Table 2. Some advantages and disadvantages of Ab-NP bio-conjugation strategies. Table adapted from $[50,51]$. 


\subsection{Clinical Applications of Nanoparticles for Cancer Therapy}

A number of untargeted NPs have entered in early phase clinical cancer trials [26]. These include cyclodextrin-polymer camptothecin-containing NPs for advanced ovarian cancer [52], micelles delivering paclitaxel to patients with advanced gastric cancer [53] and AuNPs delivering recombinant human TNFalpha to patients with advanced solid tumours [54]. Superparamagnetic Ironoxide NPs (SPIONs) have found clinical approval for use as contrast agents in cancer imaging $[55,56]$ and have also been successful in early phase trials in cancer hyperthermia $[57,58]$. Some untargeted NPs have been fully approved for clinical use as cancer therapeutics [26] including the liposomal drug PLD [59], and nanoparticle albumin-bound paclitaxel (nab-paclitaxel) [60].

Ab-targeted NPs in the clinic are showing early promise but have been so far been restricted to liposomes. In one trial, a scFv against transferrin receptor was used to target liposomes bearing p53 DNA in patients with a variety of advanced solid tumours [61]. Dose related accumulation of the transgene was observed in tumours but not in normal skin tissue. Furthermore, 7 out of 11 patients had stable disease after 6 weeks of treatment with tolerable side effects [61]. PLD has also been targeted to the FDA-approved chimeric anti-epidermal growth factor receptor (EGFR) mAb cetuximab in a phase I clinical trial with some evidence of clinical efficacy. Furthermore, the side effects seen were less severe than would be expected with either free doxorubicin or cetuximab [6] . The most common dose-limiting toxicity was myelosuppression, which could be managed prophylactically with granulocyte-colony stimulating factor (G-CSF) [6]. Targeted PLD has also been investigated in the clinic using an anti-human epidermal growth factor receptor 2 (HER-2) scFv [7]. These early clinical trials are encouraging and further translation of Ab-targeted NPs is underpinned by a number of exciting preclinical studies. The ongoing pre-clinical development of Ab-targeted NPs for delivery of cytotoxic drugs, radiotherapy and nucleic acids and their role in cancer theranostics and cancer hyperthermia is discussed below. 
4.0 Preclinical Development of antibody-targeted nanoparticles for cancer therapy

\subsection{Delivery of cytotoxic agents}

$\mathrm{Ab}$ targeted NP drug delivery offers a number of benefits over systemic administration of free drugs. These include improved intratumoural drug distribution, controlled release of drugs within the tumour microenvironment, superior efficacy and more tolerable side effects. Although antibody-targeted liposomes (immunoliposomes) remain in the lead for delivery of cytotoxic agents [62], other innovative approaches are close behind using whole Abs as well as Ab fragments. This is illustrated by the variety of drug-loaded NPs in preclinical development (Table 3). 


\begin{tabular}{|c|c|c|c|c|c|c|}
\hline Nanoparticle & $\begin{array}{l}\text { Antibody/ } \\
\text { Fragment }\end{array}$ & $\begin{array}{c}\text { Molecular } \\
\text { Target }\end{array}$ & $\begin{array}{l}\text { Cytotoxic } \\
\text { Agent }\end{array}$ & Stage & Cancer & Reference \\
\hline $\begin{array}{l}\text { PEGylated PLGA } \\
\text { Polymer }\end{array}$ & $\mathrm{mAb}$ & DR-5 & Camptothecin & In-vivo & Colorectal & [63] \\
\hline Liposome & $\mathrm{mAb}$ & GD2 & Etoposide & In-vitro & $\begin{array}{l}\text { Mixed (GD2 } \\
\text { expressing) }\end{array}$ & [64] \\
\hline $\begin{array}{l}\text { Lipid-Polymer } \\
\text { Hybrid }\end{array}$ & $\mathrm{mAb}$ & EGFR & Adriamycin & In-vivo & $\begin{array}{l}\text { Hepatocellular } \\
\text { Carcinoma (HCC) }\end{array}$ & {$[65,66]$} \\
\hline PLGA Polymer & $\mathrm{mAb}$ & EGFR & Paclitaxel & In-vivo & Lung & {$[36,67]$} \\
\hline $\begin{array}{l}\text { Porous Silica NPs } \\
\text { (pSiNPs) }\end{array}$ & $\mathrm{mAb}$ & $\begin{array}{l}\text { p75(NTR), } \\
\text { EGFR, CD20 }\end{array}$ & Camptothecin & In-vitro & $\begin{array}{l}\text { Glioblastoma, } \\
\text { Neuroblastoma, } \\
\text { B-cell lymphoma }\end{array}$ & [68] \\
\hline $\begin{array}{l}\text { Polymeric nano- } \\
\text { micelles }\end{array}$ & $\mathrm{mAb}$ & HIF- $1 \alpha$ & Paclitaxel & In-vitro & Gastric & [69] \\
\hline $\begin{array}{l}\text { Carbon Nanotube } \\
\text { (CNT) }\end{array}$ & $\mathrm{mAb}$ & CEA & Doxorubicin & In-vitro & Colon & [70] \\
\hline AuNPs & $\mathrm{mAb}$ & EGFR & Gemcitabine & In-vitro & Pancreatic & [71] \\
\hline $\begin{array}{l}\text { PLGA/MMT } \\
\text { Polymer }\end{array}$ & $\mathrm{mAb}$ & HER2 & Paclitaxel & In-vitro & Breast & [72] \\
\hline SPIONs & $\mathrm{mAb}$ & HER2 & $\begin{array}{l}\text { Paclitaxel/ } \\
\text { Rapamicin }\end{array}$ & In-vitro & Breast & {$[73]$} \\
\hline Liposome & $\mathrm{mAb}$ & $2 \mathrm{C} 5$ & Doxorubicin & In-vivo & Glioma, Lung & {$[74,75]$} \\
\hline PLA Polymer & $\mathrm{mAb}$ & $\begin{array}{l}\text { SM5-1 } \\
\text { binding } \\
\text { protein }\end{array}$ & $5-\mathrm{FU}$ & In-vivo & $\mathrm{HCC}$ & [76] \\
\hline $\begin{array}{l}\text { Lipid-Polymer } \\
\text { Hybrid (PLGA) }\end{array}$ & $\begin{array}{l}\text { Half-Ab } \\
\text { (hAb) }\end{array}$ & CEA & Paclitaxel & In-vitro & Pancreatic & [77] \\
\hline Iron-Oxide (SPION) & $\mathrm{ScFv}$ & Endoglin & Docetaxel & In-vitro & Ovarian & [66] \\
\hline PEGylated Polymer & $\mathrm{ScFv}$ & CD44v6 & $\begin{array}{l}\text { Arsenic } \\
\text { trioxide }\end{array}$ & In-vivo & Pancreatic & [67] \\
\hline PLGA Polymer & $\mathrm{ScFv}$ & $\begin{array}{l}\text { SM5-1 } \\
\text { binding } \\
\text { protein }\end{array}$ & Paclitaxel & In-vitro & HCC & [78] \\
\hline Liposome & $\mathrm{ScFv}$ & HER-2 & Doxorubicin & $\begin{array}{l}\text { Phase I } \\
\text { Clinical } \\
\text { Trial } \\
\end{array}$ & Breast & [7] \\
\hline Liposome & ScFv & c-Met & Doxorubicin & In-vivo & Lung & [79] \\
\hline PLGA & Fab & HER2 & $\begin{array}{l}\text { Pseudomonas } \\
\text { Exotoxin A } \\
\text { (PE38KDEL) }\end{array}$ & In-vivo & Breast & [80] \\
\hline Liposome & Fab & EGFR & Doxorubicin & $\begin{array}{l}\text { Phase I } \\
\text { Clinical } \\
\text { Trial }\end{array}$ & $\begin{array}{l}\text { Mixed (EGFR } \\
\text { expressing) } \\
\text { Tumour Types }\end{array}$ & {$[6,71]$} \\
\hline
\end{tabular}

Table 3. Drug-loaded NPs targeted using antibodies or antibody fragments.

Whole Abs: The majority of whole Ab targeted NPs have been directed to EGFR or

HER2; both of which have illustrated the prospect of NP-mediated intracellular

drug delivery through receptor mediated internalisation. One example used

cetuximab to target gemcitabine-loaded AuNPs [71]. In these experiments, the

authors demonstrated specific targeting of the NPs to EGFR expressing

pancreatic cell lines in-vitro and additional antibody-mediated cytotoxicity 
compared to non-targeted counterparts [71]. Targeting EGFR has also shown invivo efficacy in a range of models. For example, in delivery of paclitaxel-loaded polymeric NPs to lung tumours [36], camptothecin loaded porous silica NPs to a range of EGFR over-expressing tumours including glioblastoma [68] and adriamycin encapsulated polymer-lipid NPs to hepatocellular carcinoma [65]. In this final example, there was also evidence suggesting that both the antibody and adriamycin were contributing to the observed cytotoxicity [65]. HER2 targeting using trastuzumab has been shown to be effective using paclitaxel and rapamicin partitioned within polymer coated SPIONs; In-vitro efficacy was over 7 times higher than the non-targeted counterparts [73]. In another study, HER2-targeted polymeric NPs delivering paclitaxel showed sustained drug release in-vitro [72].

Polymeric NPs have also been successfully targeted to the pro-apoptotic cell surface death-receptor, DR5 [63]. In these experiments, the DR5-targeted polymeric NPs were shown to initiate apoptosis in-vitro and, when captothecin was encapsulated, the NP was able to overcome the resistance commonly seen with single agent anti-DR5 therapy in-vivo. In another example, hypoxia inducible factor $1 \alpha$ (HIF-1 $\alpha$ ), an extracellular protein overexpressed in a number of human cancers in response to local hypoxia, was successfully targeted with anti-HIF-1 $\alpha$ Ab functionalised paclitaxel loaded polymeric NPs [69]. The NPs were shown to selectively internalise in cells overexpressing HIF-1 $\alpha$ and paclitaxel mediated cytotoxicity was shown to be specific towards HIF-1 $\alpha$ expressing cells.Other targets investigated for controlled delivery of drug-loaded NPs include the cell surface glycoprotein and tumour marker carcinoembryonic antigen (CEA) and the p75 neurotrophin receptor (NTR) [68].NTR is a member of the tumour necrosis factor (TNF) superfamily, which has a role in cell death and is overexpressed in a number of malignancies including sarcoma and malignant melanoma [81]. Drug-loaded NPs have also been targeted using SM51, a mouse-human chimeric antibody which is highly specific to the SM5-1 binding protein, a target known to be overexpressed in a number of cancers including hepatocellular carcinoma (HCC), melanoma and breast cancer. Binding of the SM5-1 Ab to its target protein inhibits cell growth and induces apoptosis in cancer cells in a caspase dependent manner [82]. Polymeric NPs loaded with 5- 
Flurouracil (5-FU) have been successfully targeted using humanised SM5-1 in its whole $\mathrm{Ab}$ form, demonstrating sustained drug release and favourable antitumour activity against subcutaneous and orthotopic HCC xenografts [76].

PLD has been shown to exhibit enhanced tumour retention, Ab dependent endocytosis and increased cytotoxicity when targeted using the anti-nucleosome $\mathrm{mAb} 2 \mathrm{C} 5$ in orthotopic glioma tumours in-vivo [74]. The 2C5 Ab specifically recognises extracellular and tumour-cell bound nucleosomes that arise from apoptotic tumour cells in-vivo [75]. Even when used at subtherapeutic quantities, 2C5 is an effective tumour targeting moiety for PLD, also showing efficacy against primary and metastatic lung tumours in mice [75]. Central nervous system (CNS) tumours present a unique challenge to treatment due to the presence of the blood brain barrier (BBB); a unique physiological barrier which functions to protect the brain but also limits drug delivery to the CNS [83]. To facilitate movement past the BBB, polymeric, 2C5-targeted NPs have also been co-targeted using an anti-transferrin receptor (TfR) Ab. In-vivo intratumoural localisation was found to be significantly higher for the dual targeted NP than that seen for NPs targeted with each antibody alone [84]. More recently, transferrin receptor bispecific antibody platforms have been shown to successfully cross and target past the BBB [85], and these bispecific Abs could equip drug loaded NPs to more effectively target CNS tumours. These experiments suggest that $\mathrm{Ab}$ targeted NPs could offer a novel solution to deliver treatment past the BBB.

Ab Fragments: $\mathrm{Ab}$ fragments are considered to make attractive targeting agents thanks to a smaller size and potentially reduced immunogenicity compared with whole Abs [86]. The most commonly used fragments, scFvs, are readily generated using recombinant antibody technology and have been successfully applied in the following examples. ScFvs have been successfully exploited to target arsenic loaded polymeric nanoparticles targeted to CD44v6, a transmembrane glycoprotein overexpressed on pancreatic adenocarcinoma cells. Accumulation and retention within the tumour was significantly higher for CD44v6-targeted NPs than for the non-targeted controls. Furthermore, the targeted NPs inhibited tumour growth significantly more than the non-targeted 
NPs or free arsenic [67]. In another example, phage display technology was used to obtain a cell-internalising $\mathrm{scFv}$ to target c-Met; a tyrosine kinase receptor expressed on both tumour and endothelial cells [79]. When this anti-c-Met scFv was used to target PLD to lung tumours, significant disruption of the tumour vasculature was observed in addition to direct tumour cell cytotoxicity [79].

Due to their magnetic properties, it has long been proposed that SPIONs could be targeted using an externally applied magnetic field [87]. However, following successful initial in-vivo studies, problems with blood vessel embolisation led to the development of alternative methods of targeting, including Abs [88]. More recently, the possibility of magnetic targeting has been revisited in combination with an scFv targeted to endoglin, a cell surface glycoprotein overexpressed on ovarian cancer endothelial cells [66].The scFvs were conjugated to the surface of iron oxide nanoparticles pre-loaded with $\beta$-cyclodextrin encapsulated docetaxel to create drug-loaded, endoglin targeted SPIONs. In-vitro studies showed that the scFv directed specific binding onto endoglin positive cells and also that the majority of the SPIONs were localised within the magnetic field [66].

Progress has also been made using Fab-targeted NPs. For example, Fab fragments derived from a humanised anti-HER2 mAb have been successfully used to target pseudomonas exotoxin A (PE) encapsulated within PLGA NPs [80]. $\mathrm{PE}$ is a potent immunotoxin with significant toxicity, which has so far limited its use as an anti-cancer drug despite evidence of impressive anti-tumour activity [89]. The results from these experiments demonstrated improved anti-tumour activity and reduced systemic toxicity when compared to the non-encapsulated anti-HER2-PE Ab-drug conjugate (ADC).

\subsection{Delivery of radiation treatment}

Radiation is the primary treatment modality in the management of many cancers. The main challenge in radiotherapy is how to achieve adequate radiation exposure to the tumour whilst avoiding damage to surrounding healthy areas, especially in sensitive tissues such as the brain. Ab-targeted NPs have shown promise in addressing this challenge for example by facilitating 
neutron capture therapy (NCT); a technique which relies on the intratumoural injection of a non-radioactive isotope, most commonly Boron-10 $\left({ }^{10} \mathrm{~B}\right)$, which acts as a capture agent and releases localised ionising radiation [90]. In-vitro studies have targeted ${ }^{10} \mathrm{~B}$-loaded liposomes to EGFR-expressing glioma cells invitro [91], raising the possibility that Ab-targeted NPs could overcome the barrier of direct intratumoural injection of capture agents. In a second example, cetuximab-conjugated SPIONs were found to sensitise radioresistant gliomas to the effects of radiation, possibly through production of reactive oxygen species and the inhibition of DNA damage repair [92].

\subsection{Delivery of nucleic acids}

Ab-targeted NP delivery vectors such as polymeric NPs [93], AuNPs [94] and liposomes are also beginning to find a role in delivery of nucleic acids for cancer therapy. This provides opportunity for the delivery of DNA to induce expression of therapeutic tumour suppressor genes, or delivery of small interfering RNA (siRNA) or anti-sense DNA sequences which can disrupt the translation of oncogenes [95]. Encapsulation of nucleic acid in NPs aims to overcome barriers such as physiological instability, poor intracellular delivery and off-target effects [96]. For example, in one study, polyethylenimine was used to condense and compact DNA encoding the $p 53$ gene [97] generating polymer-DNA NPs which were then targeted using J591,an anti-PSMA mAb. The resultant J591 targeted NPs showed efficient transfection in various prostate cancer cell lines in-vitro and effective PSMA specific targeting when tested in-vivo in prostate cancer xenografts [97]. J591 is particularly favourable for clinical translation due to its previous use in a phase II clinical trial [98].

For delivery of anti-sense DNA, AuNPs have been coated with a highly organised anti-sense nucleic acid layer designed to bind HER2 mRNA. Corresponding sense DNA sequences were functionalised via click chemistry to anti-HER2 Abs and hybridised to the anti-sense DNA on the NP surface. These NPs had superior uptake into HER2 positive cells in-vitro compared to non-targeted counterparts. In addition, a concentration of $1 \mathrm{nM}$ anti-HER2 NPs was sufficient to completely 
block expression of HER2 in target cells whilst control NPs either containing scrambled anti-sense nucleic acids or functionalised using an off-target $\mathrm{Ab}$ control were unable to inhibit any expression [99]. A similar approach was undertaken using click chemistry to conjugate chemically stabilised antisense nucleic acids and trastuzumab to the surface of polymeric micelles. These dual functionalised polymeric NPs demonstrated HER2 targeted delivery and efficient gene knockdown in HER2 positive cells in-vitro when compared with nontargeted, non-stabilised controls [100].

Another example of efficient nucleic acid delivery utilised a liposomal formulation of antisense nucleic acids against $B C L 2$, an antiapoptotic gene overexpressed in the majority of acute leukaemias. In this study, the liposome was targeted using the anti-CD20 mAb rituximab [101]. The targeted liposomes demonstrated effective reductions of Bcl-2 protein within cancer cells. Further in-vivo studies using human Burkitt's lymphoma xenografts showed significant reductions in tumour growth. Further to this, the liposomes were found to be stable for over 1 year in storage whether as a suspension or lyophilised powder, highlighting feasibility for clinical translation [101].

\subsection{Antibody-conjugated nanoparticles as theranostic agents:}

NPs offer an attractive platform for development of so-called theranostic agents, which combine therapy and diagnosis with the aim of reducing the need for multi-step procedures and avoiding treatment delays [102]. Antibody targeting has a major role to play in this field (Figure 4), and SPIONs have become the most advanced theranostic NPs using a range of innovative approaches. One successful example of Ab-SPION theranosis used the commercial anti-EGFR mAb cetuximab, conjugated to PEG-polymer coated SPIONs through carbodiimide chemistry, to target EGFR and the mutant variant EGFRvIII expressing orthotopic glioma tumours. The mAb-functionalised SPIONs triggered apoptosis in human glioma cells in-vitro and conferred a significant survival advantage over both cetuximab and SPIONs alone when infused into orthotopic human GBM models [103]. In these innovative studies, the challenge of crossing the BBB to achieve 
adequate intratumoural distribution was addressed using convection-enhanced delivery (CED). Potent inhibition of EGFR phosphorylation and increased levels of caspase cleavage were observed along with consistent contrast enhancement of the SPIONs on T2-weighted MR. In addition to this promising experimental data, toxicity experiments in healthy mice showed no evidence of damage to normal brain tissues [103].

Targeting chemotherapy in combination with imaging agents demonstrates another theranostic approach that has been exemplified using hybrid superparamagnetic iron-platinum NPs (SIPPs) targeted to the prostate cancer target PMSA.The SIPPs were encapsulated with paclitaxel inside phospholipid micelles and then conjugated using streptavidin/biotin adaptor molecules to anti-PMSA Abs. The resulting hybrid-NPs were shown to target PMSA positive prostate cells, induce cytotoxicity similar to free paclitaxel in-vitro and function as MRI contrast agents in-vivo [104].

Iron-oxide magnetic nano-crystals (MNCs) have also been investigated for theranostic potential. These particles retain the imaging abilities of SPIONs but are smaller and do not have surface coatings. As such, they have the advantage of being readily incorporated into the structure of organic polymeric NPs to generate multifunctional NPs. In one example, doxorubicin and MNC loaded PLGA polymer nanoparticles were conjugated via carbodiimide coupling to the anti-HER2 mAb trastuzumab forming NPs with the potential to both detect and treat malignant breast cancer cells. In-vitro results with these NPs demonstrated excellent efficacy as MR probes with specificity for HER2 positive cells. As well as this, the NPs showed sustained release of doxorubicin [105]. Iron oxide MNCs have also been successfully employed as the imaging component of docetaxel loaded PLGA NPs targeted using a scFv against prostate stem cell antigen (PSCA). PSCA positive cells incubated with the targeted NPs appeared darker on T2weighted MR imaging compared with non-targeted equivalents [106]. Unusually in this study, drug release showed initial rapid desorption of drug from the particle surface, followed by more sustained release during degradation of the polymer matrix. In-vitro efficacy studies indicated that the docetaxel-loaded NPs 
were effective at a lower dose than free docetaxel. Polymeric PLGA nanoparticles have also been used to provide a vehicle for theranosis by combining doxorubicin with indocyanine green (ICG); a heat-generating near-infrared (NIR) dye [107]. When conjugated to anti-HER-2 Abs using carbodiimide chemistry, the NPs demonstrated targeted cell uptake. Furthermore, NIR laser excitation of the ICG released cytotoxic heat in-vitro. These results showcase a single theranostic NP with triple functions in (i) imaging, (ii) delivery of chemotherapy, and (iii) induction of local hyperthermia [107].

Theranostic Ab-targeted lipid based NPs have also been created using quantum dots (QDs) as the imaging component, rapamycin for therapy and trastuzumab for targeting. The resulting NPs targeted and imaged HER2 positive cells in-vitro, shown in both 2D and 3D models using confocal microscopy. In this study, lipidencapsulation alone appeared to impart a 2 fold increase in effectiveness over free rapamycin, whilst the addition of a HER2 targeting Ab imparted a further 5 fold increase in efficacy in HER2 positive cells [108].

Multi-walled carbon nanotubes (CNTs) offer new potential as cancer theranostics, due to their high carrying capacity and hyperechogenicity (increased ultrasound contrast). Preliminary results investigating the theranostic application of CNTs conjugated with Ab against PSCA have been encouraging. When functionalised with Abs, the CNTs showed efficacy as contrast agents and enhanced uptake into PSCA-expressing cells. Moreover, after loading with doxorubicin, the Ab-functionalised CNTs accumulated within tumour tissues and inhibited tumour growth in-vivo [109]. 


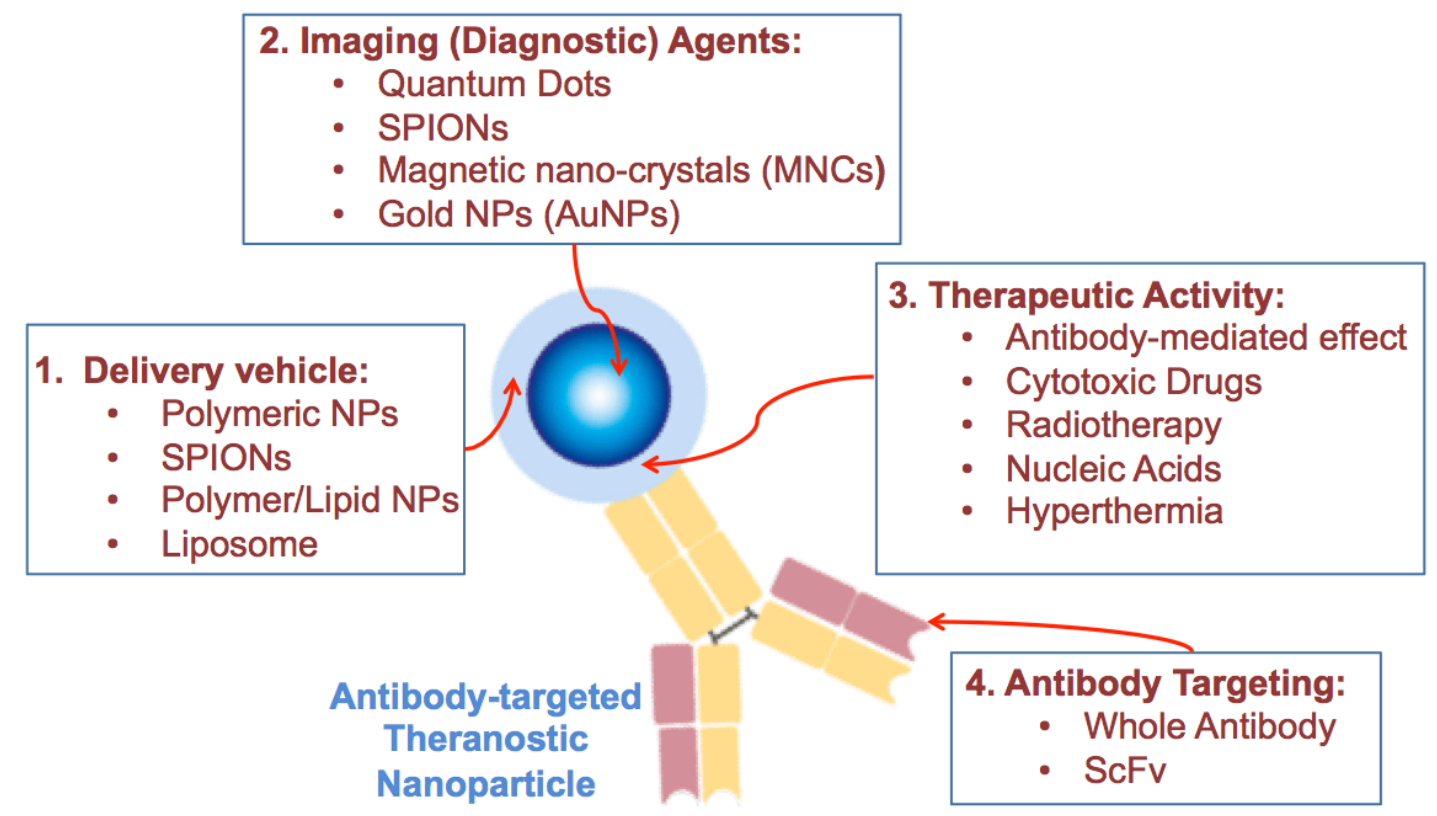

Figure 4. Schematic illustrating the 4 major components of an Ab-targeted theranostic NP: (1) Delivery vehicle, (2) Imaging agent, (3) Therapeutic component and (4) Targeting Ab. Figure adapted from [110].

\subsection{Cancer hyperthermia}

Almost 50 years ago it was shown that temperatures of just $42^{\circ} \mathrm{C}$ could induce cancer cell damage within a relatively short time frame whilst non-malignant cells were able to withstand this rise in temperature [111]. More recent work has shown that the hypoxic tumour microenvironment and the increased mitotic rate of malignant cells predispose malignant cells to temperature sensitivity [112], and that hyperthermia treatment shows synergism with conventional therapies [113]. Whilst potentially an effective treatment, the major challenge for therapeutic application of hyperthermia is restricting treatment to diseased areas and avoiding damage to healthy tissues.Heat-generating NPs offer an elegant solution to this problem, particularly if the NPs can be localised within tumours prior to heat induction. Localisation has been achieved by direct injection into tumour tissue, but increasingly antibody functionalisation is being utilised to target NPs to the tissue of interest (Table 5), as illustrated with the examples below. 


\begin{tabular}{|c|c|c|c|c|c|}
\hline Nanoparticle & $\begin{array}{c}\text { External } \\
\text { activating field }\end{array}$ & $\begin{array}{l}\text { Antibody } \\
\text { target }\end{array}$ & Setting & $\begin{array}{l}\text { Cancer } \\
\text { Treated }\end{array}$ & Reference \\
\hline $\begin{array}{r}\text { Superparamagnetic } \\
\text { Iron-oxide } \\
\text { nanoparticles } \\
\text { (SPIONs) }\end{array}$ & $\begin{array}{l}\text { Alternating } \\
\text { magnetic field } \\
(\mathrm{AMF})\end{array}$ & $\begin{array}{l}\text { Membrane } \\
\text { Protein }\end{array}$ & In-vivo & Breast & {$[114,115]$} \\
\hline \multirow[t]{5}{*}{$\begin{array}{r}\text { Gold Nanoparticles } \\
\text { (AuNPs) }\end{array}$} & \multirow[t]{2}{*}{ Laser light } & EGFR & In-vitro & $\begin{array}{l}\text { Oral Squamous } \\
\text { Cell carcinoma }\end{array}$ & [116] \\
\hline & & Mucin-7 & In-vitro & Urothelial Cells & [117] \\
\hline & \multirow{2}{*}{$\begin{array}{l}\text { Near-Infrared } \\
\text { (NIR) light }\end{array}$} & TROP-2 & In-vitro & Cervical Cancer & [118] \\
\hline & & EGFR & In-vitro & $\begin{array}{l}\text { Oral Squamous } \\
\text { Cell carcinoma }\end{array}$ & [119] \\
\hline & $\begin{array}{l}\text { Short-wave } \\
\text { radio frequency } \\
\text { (RF) energy }\end{array}$ & EGFR & In-vivo & Pancreatic & {$[120,121]$} \\
\hline \multirow{3}{*}{$\begin{array}{r}\text { Carbon Nanotubes } \\
\text { (CNTs) }\end{array}$} & \multirow[t]{3}{*}{ NIR light } & CD133 & In-vitro & Glioblastoma & [122] \\
\hline & & $\begin{array}{l}\text { HER-2 \& } \\
\text { IGF1R }\end{array}$ & In-vitro & Breast & [123] \\
\hline & & CD22/CD25 & In-vitro & $\begin{array}{l}\text { Burkitts } \\
\text { Lymphoma }\end{array}$ & {$[124]$} \\
\hline
\end{tabular}

Table 4. Ab-targeted NPs employed for cancer hyperthermia.

SPIONs: Are the most clinically advanced NPs for heat treatment due to their history of use as approved MRI contrast agents [55] and in pioneering clinical trials (untargeted) for heat treatment of glioblastoma [57]. When exposed to an alternating magnetic field (AMF) SPIONs convert magnetic energy to thermal energy through Brownian and Neel relaxation. Superparamagnetic NPs, unlike larger ferri- or ferromagnetic NPs, do not retain magnetism when the field is removed and can generate heat at lower magnetic field amplitudes, making them more attractive for biomedical applications $[125,126]$.

Antibody targeting of SPIONs for hyperthermia was first achieved by conjugating an ${ }^{111}$ In radiolabelled $\mathrm{mAb}$ against an integral membrane glycoprotein (highly expressed on a number of human cancers) to $20 \mathrm{~nm}$ dextran-coated iron-oxide nanoparticles [115]. Following intravenous injection of the NPs into in athymic mice bearing HBT 3477 (breast) xenograft tumours, mice were exposed to various levels of external AMF.Electron micrographs taken two days following AMF therapy showed tumour cell necrosis at all strengths of AMF applied. 
Tumours did not respond to either SPIONs or AMF alone, and toxicity was only seen at the highest strength of AMF applied. Subsequent statistically validated results showed that therapeutic responses were generated without normal tissue toxicity and that the heating dose correlated well with response [114]. Despite in-vivo success, subsequent studies have met with challenges due to the rapid clearance of SPIONs from circulation via the reticuloendothelial system (RES) when injected intravenously [127]. Whilst this characteristic lends itself well to SPION use as contrast agents, it is detrimental to achieving sufficient intratumoural SPION concentrations to generate therapeutic heating. A number of solutions have been proposed to overcome this, including the use of blocking agents to prolong SPION circulatory time [128], tailoring the NP surface chemistries or the targeting moieties to optimise cellular interactions of SPIONs $[41,129]$ or direct intratumoural injection with targeting antibodies functioning to retain SPIONs at the injection site.

AuNPs: Ab-targeted AuNPs have also been exploited as vectors for photothermal therapy (PTT). This process relies upon the generation of vibrational heat energy following the excitation of photosensitisers through the absorption of specific wavelengths of light; most commonly in the near-infrared (NIR) range. AuNPs strongly absorb and scatter light; this absorption can be tuned by modifications in the size and shape of the NPs in addition to the incorporation of other materials such as silica $[116,119]$. The light absorbed by AuNPs converts readily and rapidly into heat and this, along with the established biocompatibility make AuNPs attractive photothermal agents [116]. To avoid accumulation of AuNPs in healthy tissues, a number of passive and active targeting strategies have been tested to target them to tumour cells. These strategies include PEGylation, liposome encapsulation and antibody conjugation [130]. Thiol-terminated PEG derivatives are commonly used to coat the surface of AuNPs acting to improve colloidal stability, avoid the RES uptake of AuNPs and provide a 'linker' to conjugate AuNPs to biomolecules such as antibodies [131]. Recent Ab-targets investigated include trophoblast cell surface antigen 2 (TROP2), a transmembrane glycoprotein overexpressed in a number of epithelial cancers and associated with poor prognosis in cervical cancer [118]. In this study, hollow 
gold nanospheres were conjugated to anti-TROP2 mAbs using a thiol-terminated PEG linker, generating functionalised NPs able to reduce cell viability significantly more than non-targeted controls following exposure to NIR laser [118]. In another study, gold nanospheres were targeted to urothelial cancer cells using antibodies against Mucin-7; a commonly used target in bladder cancer [117], and activated using green laser light.

As well as absorbing NIR or visible light, Ab-targeted AuNPs also release heat following absorption of short-wave radio frequency (RF) energy; behaving as targeted radio frequency ablation (RFA) agents. Short-wave RF fields have the advantage of penetrating deeper into tissues than NIR light. When the anti-EGFR antibody cetuximab was conjugated to $20 \mathrm{~nm}$ gold nanorods, selective targeting was seen in-vitro and, following exposure to short-wave RF fields, necrotic cellular injury was achieved; similar to the effects of invasive RFA in the clinic [120]. When the same NPs were tested in-vivo, significant cell death was observed 36 hours following treatment of EGFR amplified pancreatic xenograft tumours, with no damage in selected healthy tissues including the liver [121].

CNTs: NIR activated Ab-targeted CNTs have also been employed to induce PTT in-vitro [132]. Examples of targets investigated include HER2 and IGF1R, to target CNTs to breast cancer cells [123], CD22 and CD25 to target Burkitts lymphoma [124] and CD133 to target glioma-like stem cells in the treatment of glioblastoma [122]. Whilst these early studies show promise, CNTs accumulate in the liver, are non-biodegradable, and show poor solubility with a tendency to aggregate. These challenges of toxicity limit the current clinical translation of CNTs, and are being addressed [133].

\subsection{Conclusions}

This review has illustrated the ways in which the diversity and versatility of NPs can be further exploited by $\mathrm{Ab}$ targeting. A wide range of pre-clinical research has demonstrated that Ab-targeted NPs can be used to delivery cytotoxic chemotherapy directly to cancer cells, resulting in efficacious treatment with 
reduced side effects profiles compared to free drugs. Breakthroughs have also been made in utilising Ab-NPs to augment radiotherapy and aid in cancer gene therapy. Cancer theranostics has evolved in parallel to NPs, and a number of innovative approaches have showcased single agents, which can combine cancer imaging and therapy. Finally, the use of hyperthermia in the treatment of cancers has been made possible thanks to the inherent physical properties of SPIONs, AuNPs and CNTs.

Targeted therapy remains at the forefront of translational cancer research and significant progress has been made in the clinical translation of antibodytargeted NP based cancer treatment, including phase I clinical trials using antibody targeted drug-loaded liposomes. These pioneering studies have built upon previous successes developing NPs, refining bio-conjugation strategies and optimising the biocompatibility and bioavailability of these products.

\subsection{Future Perspectives}

Future research on Ab-NPs will depend upon reliable and reproducible bioconjugation strategies that can be scaled up to good manufacturing practice (GMP) standard for clinical translation [129]. Other NPs such as mesoporous silica NPs (MSNs) (Table 1) could be utilised which offer impressive drug carrying capacity, and can be equipped with targeting ligands [134]. In addition, multifunctional hybrid NPs can be generated for use in combination therapy and/or theranostics.

The role of immunotherapy in the treatment of cancer continues to evolve. Whilst the use of Ab-targeted NPs in cancer immunotherapy is early in development [135], recent breakthroughs include the use of PLGA NPs conjugated to both protein-MHC complexes and anti-CD28 mAbs to act as synthetic antigen presenting vehicles when administered in-vitro [136]. In the future, Ab-targeted NPs could be used to prime the immune system not only to recognise tumour antigens but also to stimulate anti-tumour immunity. Whilst Ab-targeted NPs are only just reaching the clinical setting, their diverse potential 
for use in cancer diagnostics and therapeutics predicts an important role in the future of cancer treatment.

\subsection{Executive Summary}

Introduction

- Targeted cancer treatment offers significant advantages over conventional therapy but current targeted treatments are often limited by systemic toxicity

- Nanoparticles (NPs) possess unique physical, chemical and biological properties that could overcome these limitations and be harnessed for use in cancer medicine

Nanoparticles

- NPs are naturally occurring or manufactured particulate material either unbound, as an aggregate or agglomerate with one dimension between 1 and $100 \mathrm{~nm}$ in size.

- NPs possess interrelated properties; high mobility in the free state, large surface area to volume ratios, and sometimes the exhibition of quantum effects.

- The wide and diverse range of functional properties exhibited by NPs is possible thanks to the utility of a variety of materials to synthesise them.

Targeting nanoparticles for cancer treatment

- Passive accumulation of NPs occurs within malignant tissues in a process known as enhanced permeability and retention (EPR).

- Specific targeting of NPs to cancer cells can be achieved through the addition of a targeting moiety, including proteins, small molecules and aptamers.

- Antibodies (Abs) are the most promising targeting ligands and can be readily generated as intact IgG molecules or as fragments (ScFvs) in defined, recombinant form.

- Antibody targeting is complementary to EPR and enables specific receptor mediated internalization of the NP.

Antibody-Nanoparticle bio-conjugation strategies

- Challenges in bio-conjugation can be broadly divided into three main categories; (i) controllability, (ii) stability, and (iii) reliability.

- Sophisticated conjugation techniques enable the control of antibody orientations to ensure target binding and preserve Ab bioactivity

- Whilst both bifunctional linker molecules and adaptor molecules can generate functional conjugates, covalent linker molecules demonstrate superior long term stability.

- Established covalent conjugation strategies include carbodiimide coupling, maleimide coupling and click chemistry (copper catalyzed alkyne-azide cycloaddition reactions).

Clinical Applications of Nanoparticles for Cancer Therapy

- NP based drug-delivery systems successfully translated into early phase clinical trials include liposomes, polymeric NPs, dendrimers, micelles and gold NPs (AuNPs).

- Superparamagnetic Iron-oxide NPs (SPIONs) have been clinically approved for use as contrast agents in cancer imaging and have been successful in early phase trials for cancer hyperthermia

- Antibody-targeted liposomes (immunoliposomes) have been used in three early phase clinical trials.

Preclinical Development of antibody-targeted nanoparticles for cancer therapy

- Chemotherapy loaded Ab-NPs can offer improved intratumoural drug delivery, superior efficacy compared with free drugs, and controlled release of drugs within tumour cells.

- Targeting past the blood brain barrier (BBB) to target central nervous system (CNS) tumours may be possible through dual targeting of transferrin receptor and cancer specific targets.

- Ab-targeted polymeric NPs, AuNPs and liposomes can be used to stabilise nucleic acids and deliver them directly to cancer cells for gene therapy.

- SPIONs be combined with other NPs including polymers and quantum dots to produce multi-functional theranostic NPs that can image tumours and delivery cytotoxic drugs in combination

- SPIONs, AuNPs and CNTs are able to generate heat from within the tissue of interest when activated by externally applied alternating magnetic fields (SPIONs) or nearinfrared fields (AuNPs/CNTs). 
- SPIONs have been targeted using Abs in the pre-clinical setting with success limited by rapid uptake by the reticuloendothelial system and clearance in-vivo. Strategies are being investigated to reduce this uptake.

Conclusions

- Ab-targeted NPs offer a versatile platform for the development of the next generation of cancer therapeutics

- Progress has been made in the clinical translation of antibody-targeted NP based cancer treatments

Future Perspectives

- Reliable and reproducible bio-conjugation strategies that can be scaled up to good manufacturing practice (GMP) standard will facilitate clinical translation of Ab-targeted NPs.

- Ab-targeted NPs may have a future role in cancer immunotherapy, including in the development of synthetic antigen-presenting vehicles.

Financial \& competing interests disclosure

The authors are grateful for the support received from the Seventh Framework Programme (FP7) for DARPin targeted magnetic hyperthermic therapy for glioblastoma (Dartrix EC GRANT: 278580), and from the Department of Health and Cancer Research UK Experimental Cancer Medicine Centre (ECMC). The authors have no other relevant affiliations of financial involvement with any organization or entity with financial interest in or financial conflict with the subject matter or materials discussed in the manuscript apart from those disclosed. The funders had no role in study design, data collection and analysis, decision to publish, or preparation of the manuscript

No writing assistance was utilised in the production of this manuscript.

\section{Bibliography}

1. Jarboe J, Gupta A, Saif W. Therapeutic human monoclonal antibodies against cancer. In: Human Monoclonal Antibodies, (Ed.^(Eds).Springer 6177 (2014).

2. Leal M, Sapra P, Hurvitz SA et al. Antibody-drug conjugates: an emerging modality for the treatment of cancer. Ann. N. Y. Acad. Sci. 1321(1), 41-54 (2014).

3. Honeychurch J, Cheadle EJ, Dovedi SJ, Illidge TM. Immuno-regulatory antibodies for the treatment of cancer. Expert Opin. Biol. Ther. (0), 1-15 (2015).

4. Huehls AM, Coupet TA, Sentman CL. Bispecific T-cell engagers for cancer immunotherapy. Immunol. Cell. Biol. (2014).

5. Fay F, Scott CJ. Antibody-targeted nanoparticles for cancer therapy. Immunotherapy 3(3), 381-394 (2011).

6. Mamot C, Ritschard R, Wicki A et al. Tolerability, safety, pharmacokinetics, and efficacy of doxorubicin-loaded anti-EGFR immunoliposomes in advanced solid tumours: a phase 1 doseescalation study. Lancet Oncol. 13(12), 1234-1241 (2012). 


\section{* A phase I clinical trial of an antibody-targeted liposome}

7. Munster PN, Miller K, Krop IE et al. A Phase I study of MM-302, a HER2targeted liposomal doxorubicin, in patients with advanced, HER2-positive (HER2+) breast cancer. Presented at: ASCO Annual Meeting. Chicago, IL, USA. 2012.

8. Hrkach J, Von Hoff D, Ali MM et al. Preclinical development and clinical translation of a PSMA-targeted docetaxel nanoparticle with a differentiated pharmacological profile. Sci. Transl. Med. 4(128), 128ra139128ra139 (2012).

9. Bertrand N, Wu J, Xu X, Kamaly N, Farokhzad OC. Cancer nanotechnology: The impact of passive and active targeting in the era of modern cancer biology. Adv. Drug Deliv. Rev. 66 2-25 (2014).

\section{* Recent review covering cancer targeting}

10. Chou L, Ming K, Chan W. Strategies for the intracellular delivery of nanoparticles. Chem. Soc. Rev. 40(1), 233 (2011).

11. Bleeker EaJ, De Jong WH, Geertsma RE et al. Considerations on the EU definition of a nanomaterial: Science to support policy making. Regul. Toxicol. Pharmacol. 65(1), 119-125 (2013).

12. Kreyling WG, Semmler-Behnke M, Chaudhry Q. A complementary definition of nanomaterial. Nano Today 5(3), 165-168 (2010).

13. Auffan M, Rose J, Bottero J-Y, Lowry GV, Jolivet J-P, Wiesner MR. Towards a definition of inorganic nanoparticles from an environmental, health and safety perspective. Nat. Nanotechnol. 4(10), 634-641 (2009).

14. Dobson P, Jarvie, H., King, S.,. Nanoparticle. Encyclopedia Britannica http://www.britannica.com/science/nanoparticle (2015).

15. Elzoghby AO, Samy WM, Elgindy NA. Albumin-based nanoparticles as potential controlled release drug delivery systems. J. Control. Release 157(2), 168-182 (2012).

16. Kumari A, Yadav SK, Yadav SC. Biodegradable polymeric nanoparticles based drug delivery systems. Colloids Surf., B 75(1), 1-18 (2010).

17. Garg T, K Goyal A. Liposomes: targeted and controlled delivery system. Drug Deliv. Lett. 4(1), 62-71 (2014).

18. Mohamed S, Parayath NN, Taurin S, Greish K. Polymeric nano-micelles: versatile platform for targeted delivery in cancer. Ther. Deliv. 5(10), 11011121 (2014).

19. Abbasi E, Aval SF, Akbarzadeh A et al. Dendrimers: synthesis, applications, and properties. Nanoscale Res. Lett. 9(1), 1-10 (2014). 
20. Kaminskas LM, Boyd BJ, Porter CJ. Dendrimer pharmacokinetics: the effect of size, structure and surface characteristics on ADME properties. Nanomedicine 6(6), 1063-1084 (2011).

21. Mok H, Zhang M. Superparamagnetic Iron Oxide Nanoparticle-Based Delivery Systems for Biotherapeutics. Expert Opin. Drug Deliv. 10(1), 7387 (2013).

22. Rosenholm JM, Mamaeva V, Sahlgren C, Lindén M. Nanoparticles in targeted cancer therapy: mesoporous silica nanoparticles entering preclinical development stage. Nanomedicine 7(1), 111-120 (2012).

23. Cabral RM, Baptista PV. Anti-cancer precision theranostics: a focus on multifunctional gold nanoparticles. Expert Rev. Mol. Diagn. 14(8), 10411052 (2014).

24. Rastogi V, Yadav P, Bhattacharya SS et al. Carbon Nanotubes: An Emerging Drug Carrier for Targeting Cancer Cells. J. Drug Deliv. 2014670815 (2014).

25. Valizadeh A, Mikaeili H, Samiei M et al. Quantum dots: synthesis, bioapplications, and toxicity. Nanoscale Res. Lett. 7(1), 1-14 (2012).

26. Sun T, Zhang YS, Pang B, Hyun DC, Yang M, Xia Y. Engineered nanoparticles for drug delivery in cancer therapy. Angew. Chem. Int. Ed. 53(46), 12320-12364 (2014).

27. Greish K. Enhanced permeability and retention (EPR) effect for anticancer nanomedicine drug targeting. In: Cancer Nanotechnol., (Ed.^(Eds).Springer 25-37 (2010).

28. Ye H, Karim AA, Loh XJ. Current treatment options and drug delivery systems as potential therapeutic agents for ovarian cancer: A review. Mat. Sci. Eng. C Mater. Biol. Appl. 45(0), 609-619 (2014).

29. Bae YH, Park K. Targeted drug delivery to tumors: myths, reality and possibility. J. Control. Release 153(3), 198 (2011).

30. Bazak R, Houri M, El Achy S, Kamel S, Refaat T. Cancer active targeting by nanoparticles: a comprehensive review of literature. J. Cancer Res. Clin. Oncol. doi:10.1007/s00432-014-1767-3 1-16 (2014).

31. Mccafferty J, Schofield D. Identification of optimal protein binders through the use of large genetically encoded display libraries. Curr. Opin. Chem. Biol 26 16-24 (2015).

32. Weiner LM, Surana R, Wang S. Monoclonal antibodies: versatile platforms for cancer immunotherapy. Nat. Rev. Immunol. 10(5), 317-327 (2010).

33. Liu P, Li Z, Zhu M et al. Preparation of EGFR monoclonal antibody conjugated nanoparticles and targeting to hepatocellular carcinoma. J. Mater. Sci. Mater. Med. 21(2), 551-556 (2010). 
34. Kirpotin DB, Drummond DC, Shao Y et al. Antibody Targeting of LongCirculating Lipidic Nanoparticles Does Not Increase Tumor Localization but Does Increase Internalization in Animal Models. Cancer Res. 66(13), 6732-6740 (2006).

35. Marega R, Karmani L, Flamant L et al. Antibody-functionalized polymercoated gold nanoparticles targeting cancer cells: an in vitro and in vivo study. J. Mater. Chem. 22(39), 21305-21312 (2012).

36. Karra N, Nassar T, Ripin AN, Schwob 0, Borlak J, Benita S. Antibody Conjugated PLGA Nanoparticles for Targeted Delivery of Paclitaxel Palmitate: Efficacy and Biofate in a Lung Cancer Mouse Model. Small 9(24), 4221-4236 (2013).

37. Puertas S, Moros M, Fernández-Pacheco R, Ibarra M, Grazú V, De La Fuente J. Designing novel nano-immunoassays: antibody orientation versus sensitivity. J. Phys. D: Appl. Phys. 43(47), 474012 (2010).

38. Sperling RA, Pellegrino T, Li JK, Chang WH, Parak WJ. Electrophoretic separation of nanoparticles with a discrete number of functional groups. Adv. Funct. Mater. 16(7), 943-948 (2006).

39. Lin P-C, Chen S-H, Wang K-Y et al. Fabrication of oriented antibodyconjugated magnetic nanoprobes and their immunoaffinity application. Anal. Chem. 81(21), 8774-8782 (2009).

40. Kumar S, Aaron J, Sokolov K. Directional conjugation of antibodies to nanoparticles for synthesis of multiplexed optical contrast agents with both delivery and targeting moieties. Nat. Protoc. 3(2), 314-320 (2008).

41. Grüttner C, Müller K, Teller J, Westphal F. Synthesis and functionalisation of magnetic nanoparticles for hyperthermia applications. Int. J. Hyperthermia 29(8), 777-789 (2013).

42. Grüttner C, Müller K, Teller J, Westphal F, Foreman A, Ivkov R. Synthesis and antibody conjugation of magnetic nanoparticles with improved specific power absorption rates for alternating magnetic field cancer therapy. J. Magn. Magn. Mater. 311(1), 181-186 (2007).

43. Pathak S, Davidson MC, Silva GA. Characterization of the functional binding properties of antibody conjugated quantum dots. Nano Lett. 7(7), 1839-1845 (2007).

44. Aubin-Tam M-E, Hamad-Schifferli K. Structure and function of nanoparticle-protein conjugates. Biomed. Mater. 3(3), 034001 (2008).

45. Wartlick H, Michaelis K, Balthasar S, Strebhardt K, Kreuter J, Langer K. Highly Specific HER2-mediated Cellular Uptake of Antibody-modified Nanoparticles in Tumour Cells. J. Drug Target. 12(7), 461-471 (2004). 
46. Steinhauser I, Spänkuch B, Strebhardt K, Langer K. Trastuzumab-modified nanoparticles: Optimisation of preparation and uptake in cancer cells. Biomaterials 27(28), 4975-4983 (2006).

47. Veiseh O, Gunn JW, Zhang M. Design and fabrication of magnetic nanoparticles for targeted drug delivery and imaging. Adv. Drug Deliv. Rev. 62(3), 284-304 (2010).

48. Thanh NT, Green LA. Functionalisation of nanoparticles for biomedical applications. Nano Today 5(3), 213-230 (2010).

49. Ghosh P, Han G, De M, Kim CK, Rotello VM. Gold nanoparticles in delivery applications. Adv. Drug Deliv. Rev. 60(11), 1307-1315 (2008).

50. Montenegro J-M, Grazu V, Sukhanova A et al. Controlled antibody/(bio-) conjugation of inorganic nanoparticles for targeted delivery. Adv. Drug Deliv. Rev. 65(5), 677-688 (2013).

* Review on the challenges and techniques in bio-conjugation of antibodies and nanoparticles

51. Kao C-H, Wang J-Y, Chuang K-H et al. One-step mixing with humanized anti-mPEG bispecific antibody enhances tumor accumulation and therapeutic efficacy of mPEGylated nanoparticles. Biomaterials 35(37), 9930-9940 (2014).

52. Pham E, Birrer MJ, Eliasof S et al. Translational impact of nanoparticledrug conjugate CRLX101 with or without bevacizumab in advanced ovarian cancer. Clin. Cancer Res. 21(4), 808-818 (2015).

53. Kato K, Chin K, Yoshikawa T et al. Phase II study of NK105, a paclitaxelincorporating micellar nanoparticle, for previously treated advanced or recurrent gastric cancer. Invest. New Drugs 30(4), 1621-1627 (2012).

54. Libutti SK, Paciotti GF, Byrnes AA et al. Phase I and pharmacokinetic studies of CYT-6091, a novel PEGylated colloidal gold-rhTNF nanomedicine. Clin. Cancer Res. 16(24), 6139-6149 (2010).

55. Reimer P, Balzer T. Ferucarbotran (Resovist): a new clinically approved RES-specific contrast agent for contrast-enhanced MRI of the liver: properties, clinical development, and applications. Eur. Radiol. 13(6), 1266-1276 (2003).

56. Wang Y-XJ. Superparamagnetic iron oxide based MRI contrast agents: Current status of clinical application. Quant. Imaging Med. Surg.y 1(1), 3540 (2011).

57. Maier-Hauff K, Ulrich F, Nestler D et al. Efficacy and safety of intratumoral thermotherapy using magnetic iron-oxide nanoparticles combined with external beam radiotherapy on 
patients with recurrent glioblastoma multiforme. J. Neurooncol. 103(2), 317-324 (2011).

* Phase II clinical trial of non-targeted SPION mediated magnetic hyperthermia in combination with extrenal beam radiation

58. Maier-Hauff K, Rothe R, Scholz R et al. Intracranial Thermotherapy using Magnetic Nanoparticles Combined with External Beam Radiotherapy:

Results of a Feasibility Study on Patients with Glioblastoma Multiforme. J. Neurooncol. 81(1), 53-60 (2007).

59. Allen TM, Cullis PR. Liposomal drug delivery systems: from concept to clinical applications. Adv. Drug Deliv. Rev. 65(1), 36-48 (2013).

60. Von Hoff DD, Ervin T, Arena FP et al. Increased survival in pancreatic cancer with nab-paclitaxel plus gemcitabine. N. Engl. J. Med. 369(18), 1691-1703 (2013).

61. Senzer N, Nemunaitis J, Nemunaitis D et al. Phase I study of a systemically delivered p53 nanoparticle in advanced solid tumors. Mol. Ther. 21(5), 1096-1103 (2013).

62. Paszko E, Senge M. Immunoliposomes. Curr. Med. Chem. 19(31), 52395277 (2012).

63. Schmid D, Fay F, Small DM et al. Efficient Drug Delivery and Induction of Apoptosis in Colorectal Tumors Using a Death Receptor 5-Targeted Nanomedicine. Mol. Ther. 22(12), 2083-2092 (2014).

64. Brown BS, Patanam T, Mobli K et al. Etoposide-loaded immunoliposomes as active targeting agents for GD2-positive malignancies. Cancer Biol. Ther. 15(7), 851-861 (2014).

65. Gao J, Xia Y, Chen H et al. Polymer-lipid hybrid nanoparticles conjugated with anti-EGF receptor antibody for targeted drug delivery to hepatocellular carcinoma. Nanomedicine 9(2), 279-293 (2013).

66. Huang X, Yi C, Fan Y et al. Magnetic Fe304 nanoparticles grafted with single-chain antibody (scFv) and docetaxel loaded $\beta$-cyclodextrin potential for ovarian cancer dual-targeting therapy. Mater. Sci. Eng., $C$ 42(0), 325-332 (2014).

67. Qian C, Wang Y, Chen Y et al. Suppression of pancreatic tumor growth by targeted arsenic delivery with anti-CD44v6 single chain antibody conjugated nanoparticles. Biomaterials 34(26), 6175-6184 (2013).

68. Secret E, Smith K, Dubljevic V et al. Antibody - Functionalized Porous Silicon Nanoparticles for Vectorization of Hydrophobic Drugs. Adv. Healthc. Mater. 2(5), 718-727 (2013). 
69. Song $\mathrm{H}, \mathrm{He} \mathrm{R}$, Wang K et al. Anti-HIF-1 $\alpha$ antibody-conjugated pluronic triblock copolymers encapsulated with Paclitaxel for tumor targeting therapy. Biomaterials 31(8), 2302-2312 (2010).

70. Heister E, Neves V, Tîlmaciu C et al. Triple functionalisation of singlewalled carbon nanotubes with doxorubicin, a monoclonal antibody, and a fluorescent marker for targeted cancer therapy. Carbon 47(9), 2152-2160 (2009).

71. Patra CR, Bhattacharya R, Wang E et al. Targeted delivery of gemcitabine to pancreatic adenocarcinoma using cetuximab as a targeting agent. Cancer Res. 68(6), 1970-1978 (2008).

72. Sun B, Ranganathan B, Feng S-S. Multifunctional poly (D, L-lactide-coglycolide)/montmorillonite (PLGA/MMT) nanoparticles decorated by Trastuzumab for targeted chemotherapy of breast cancer. Biomaterials 29(4), 475-486 (2008).

73. Dilnawaz F, Singh A, Mohanty C, Sahoo SK. Dual drug loaded superparamagnetic iron oxide nanoparticles for targeted cancer therapy. Biomaterials 31(13), 3694-3706 (2010).

74. Gupta B, Torchilin VP. Monoclonal antibody 2C5-modified doxorubicinloaded liposomes with significantly enhanced therapeutic activity against intracranial human brain U-87 MG tumor xenografts in nude mice. Cancer Immunol. Immunother. 56(8), 1215-1223 (2007).

75. Elbayoumi TA, Torchilin VP. Tumor-specific anti-nucleosome antibody improves therapeutic efficacy of doxorubicin-loaded long-circulating liposomes against primary and metastatic tumor in mice. Mol. Pharm. 6(1), 246-254 (2008).

76. Ma X, Cheng Z, Jin Y et al. SM5-1-conjugated PLA nanoparticles loaded with 5 -fluorouracil for targeted hepatocellular carcinoma imaging and therapy. Biomaterials 35(9), 2878-2889 (2014).

77. Hu C-MJ, Kaushal S, Cao HST et al. Half-antibody functionalized lipidpolymer hybrid nanoparticles for targeted drug delivery to carcinoembryonic antigen presenting pancreatic cancer cells. Mol. Pharm. 7(3), 914-920 (2010).

78. Kou G, Gao J, Wang H et al. Preparation and characterization of paclitaxelloaded PLGA nanoparticles coated with cationic SM5-1 single-chain antibody. J. Biochem. Mol. Biol. 40(5), 731-739 (2007).

79. Lu R-M, Chang Y-L, Chen M-S, Wu H-C. Single chain anti-c-Met antibody conjugated nanoparticles for in vivo tumor-targeted imaging and drug delivery. Biomaterials 32(12), 3265-3274 (2011). 
80. Gao J, Kou G, Wang H et al. PE38KDEL-loaded anti-HER2 nanoparticles inhibit breast tumor progression with reduced toxicity and immunogenicity. Breast Cancer Res. Treat. 115(1), 29-41 (2009).

81. Dan P. The Role of Neurotrophin Receptor p75NTR in Cancer.

82. Dai J, Jin J, Li B et al. A chimeric SM5-1 antibody inhibits hepatocellular carcinoma cell growth and induces caspase-dependent apoptosis. Cancer Lett. 258(2), 208-214 (2007).

83. Chen Y, Liu L. Modern methods for delivery of drugs across the bloodbrain barrier. Adv. Drug Deliv. Rev. 64(7), 640-665 (2012).

84. Fujita M, Lee B-S, Khazenzon NM et al. Brain tumor tandem targeting using a combination of monoclonal antibodies attached to biopoly ( $\beta$-Lmalic acid). J. Control. Release 122(3), 356-363 (2007).

85. Yu YJ, Atwal JK, Zhang Y et al. Therapeutic bispecific antibodies cross the blood-brain barrier in nonhuman primates. Sci. Transl. Med. 6(261), 261ra154-261ra154 (2014).

86. Holliger P, Hudson PJ. Engineered antibody fragments and the rise of single domains. Nature biotechnol. 23(9), 1126-1136 (2005).

87. Widder KJ, Senyei AE, Scarpelli DG. Magnetic Microspheres: A Model System for Site Specific Drug Delivery in Vivo. Exp. Biol. Med. 158(2), 141146 (1978).

88. Pankhurst QA, Connolly J, Jones S, Dobson J. Applications of magnetic nanoparticles in biomedicine. J. Phys D: Appl. Phys. 36(13), R167 (2003).

89. Pastan I, Hassan R, Fitzgerald DJ, Kreitman RJ. Immunotoxin treatment of cancer*. Annu. Rev. Med. 58 221-237 (2007).

90. Barth RF, Vicente M, Harling OK et al. Current status of boron neutron capture therapy of high grade gliomas and recurrent head and neck cancer. Radiat. Oncol. 7(146), 1-21 (2012).

91. Pan X, Wu G, Yang W, Barth RF, Tjarks W, Lee RJ. Synthesis of cetuximabimmunoliposomes via a cholesterol-based membrane anchor for targeting of EGFR. Bioconjugate Chem. 18(1), 101-108 (2007).

92. Bouras A, Kaluzova M, Hadjipanayis CG. Radiosensitivity enhancement of radioresistant glioblastoma by epidermal growth factor receptor antibody-conjugated iron-oxide nanoparticles. J. Neurooncol. 1-10 (2015).

93. Kim J, Wilson DR, Zamboni CG, Green JJ. Targeted polymeric nanoparticles for cancer gene therapy. J. Drug Target. 23(7-8), 627-641 (2015).

94. Ding Y, Jiang Z, Saha K et al. Gold nanoparticles for nucleic acid delivery. Mol. Ther. 22(6), 1075-1083 (2014). 
95. Walther W, Schlag PM. Current status of gene therapy for cancer. Curr. Opin. Oncol. 25(6), 659-664 (2013).

96. Xu C-F, Wang J. Delivery systems for siRNA drug development in cancer therapy. Asian J. Pharmaceutical Sci. 10(1), 1-12 (2015).

97. Moffatt S, Papasakelariou C, Wiehle S, Cristiano R. Successful in vivo tumor targeting of prostate-specific membrane antigen with a highly efficient J591/PEI/DNA molecular conjugate. Gene Ther. 13(9), 761-772 (2006).

98. Tagawa ST, Milowsky MI, Morris M et al. Phase II Study of Lutetium-177Labeled Anti-Prostate-Specific Membrane Antigen Monoclonal Antibody J591 for Metastatic Castration-Resistant Prostate Cancer. Clin. Cancer Res. 19(18), 5182-5191 (2013).

99. Zhang K, Hao L, Hurst SJ, Mirkin CA. Antibody-linked spherical nucleic acids for cellular targeting. J. Am. Chem. Soc. 134(40), 16488-16491 (2012).

100. Chan DP, Deleavey GF, Owen SC, Damha MJ, Shoichet MS. Click conjugated polymeric immuno-nanoparticles for targeted siRNA and antisense oligonucleotide delivery. Biomaterials 34(33), 8408-8415 (2013).

101. Meissner JM, Toporkiewicz M, Czogalla A, Matusewicz L, Kuliczkowski K, Sikorski AF. Novel antisense therapeutics delivery systems: In vitro and in vivo studies of liposomes targeted with anti-CD20 antibody. J. Control. Release 220 515-528 (2015).

102. Shanbhag PP, Jog SV, Chogale MM, Gaikwad SS. Theranostics for cancer therapy. Curr. Drug Deliv. 10(3), 357-362 (2013).

103. Kaluzova M, Bouras A, Machaidze R, Hadjipanayis C. Targeted therapy of glioblastoma stem-like cells and tumor non-stem cells using cetuximab-conjugated iron-oxide nanoparticles. Oncotarget 6(11), 8788-8806 (2015).

\section{* Pioneering study infusing EGFR-targeted SPIONs into tumours using convection enhanced delivery for theranostic application}

104. Taylor RM, Sillerud LO. Paclitaxel-loaded iron platinum stealth immunomicelles are potent MRI imaging agents that prevent prostate cancer growth in a PSMA-dependent manner. Int. J. Nanomedicine 74341 (2012).

105. Yang J, Lee C-H, Park J et al. Antibody conjugated magnetic PLGA nanoparticles for diagnosis and treatment of breast cancer. J. Mater. Chem. 17(26), 2695-2699 (2007). 
106. Ling Y, Wei K, Luo Y, Gao X, Zhong S. Dual docetaxel/superparamagnetic iron oxide loaded nanoparticles for both targeting magnetic resonance imaging and cancer therapy. Biomaterials 32(29), 7139-7150 (2011).

107. Srinivasan S, Manchanda R, Lei T, Nagesetti A, Fernandez-Fernandez A, Mcgoron AJ. Targeted nanoparticles for simultaneous delivery of chemotherapeutic and hyperthermia agents - An in vitro study. J. Photochem. Photobiol. B. 136(0), 81-90 (2014).

108. Parhi P, Sahoo SK. Trastuzumab guided nanotheranostics: A lipid based multifunctional nanoformulation for targeted drug delivery and imaging in breast cancer therapy. J. Colloid Interface Sci. 451 198-211 (2015).

109. Wu H, Shi H, Zhang $\mathrm{H}$ et al. Prostate stem cell antigen antibody-conjugated multiwalled carbon nanotubes for targeted ultrasound imaging and drug delivery. Biomaterials 35(20), 5369-5380 (2014).

110. Menon JU, Jadeja P, Tambe P, Vu K, Yuan B, Nguyen KT. Nanomaterials for photo-based diagnostic and therapeutic applications. Theranostics 3(3), 152-166 (2013).

111. Cavaliere R, Ciocatto EC, Giovanella BC et al. Selective heat sensitivity of cancer cells. Biochemical and clinical studies. Cancer 20(9), 1351-1381 (1967).

112. Hildebrandt $\mathrm{B}, \mathrm{Wust} \mathrm{P}, \mathrm{Ahlers} \mathrm{O}$ et al. The cellular and molecular basis of hyperthermia. Crit. Rev. Oncol. Hematol. 43(1), 33-56 (2002).

113. Hurwitz M, Stauffer P. Hyperthermia, radiation and chemotherapy: the role of heat in multidisciplinary cancer care. Presented at: Semin. Oncol. 2014.

114. Denardo SJ, Denardo GL, Natarajan A et al. Thermal dosimetry predictive of efficacy of 111In-ChL6 nanoparticle AMF-induced thermoablative therapy for human breast cancer in mice. J. Nucl. Med. 48(3), 437-444 (2007).

115. Denardo SJ, Denardo GL, Miers LA et al. Development of Tumor Targeting Bioprobes (111In-Chimeric L6 Monoclonal Antibody Nanoparticles) for Alternating Magnetic Field Cancer Therapy. Clin. Cancer Res. 11(19), 7087s-7092s (2005).

116. El-Sayed IH, Huang X, El-Sayed MA. Selective laser photo-thermal therapy of epithelial carcinoma using anti-EGFR antibody conjugated gold nanoparticles. Cancer Lett. 239(1), 129-135 (2006).

117. Chen CH, Wu Y-J, Chen J-J. Gold Nanotheranostics: Photothermal Therapy and Imaging of Mucin 7 Conjugated Antibody Nanoparticles for Urothelial Cancer. BioMed Res. Int. (2014). 
118. Liu T, Tian J, Chen Z et al. Anti-TROP2 conjugated hollow gold nanospheres as a novel nanostructure for targeted photothermal destruction of cervical cancer cells. Nanotechnology 25(34), 345103 (2014).

119. Huang X, El-Sayed IH, Qian W, El-Sayed MA. Cancer cell imaging and photothermal therapy in the near-infrared region by using gold nanorods. J. Am. Chem. Soc. 128(6), 2115-2120 (2006).

120. Glazer ES, Massey KL, Zhu C, Curley SA. Pancreatic carcinoma cells are susceptible to noninvasive radio frequency fields after treatment with targeted gold nanoparticles. Surgery 148(2), 319-324 (2010).

121. Glazer ES, Zhu C, Massey KL et al. Noninvasive radiofrequency field destruction of pancreatic adenocarcinoma xenografts treated with targeted gold nanoparticles. Clin. Cancer Res. 16(23), 5712-5721 (2010).

122. Wang C-H, Chiou S-H, Chou C-P, Chen Y-C, Huang Y-J, Peng C-A. Photothermolysis of glioblastoma stem-like cells targeted by carbon nanotubes conjugated with CD133 monoclonal antibody. Nanomed. Nanotech. Biol. Med. 7(1), 69-79 (2011).

123. Shao N, Lu S, Wickstrom E, Panchapakesan B. Integrated molecular targeting of IGF1R and HER2 surface receptors and destruction of breast cancer cells using single wall carbon nanotubes. Nanotechnology 18(31), 315101 (2007).

124. Marches R, Chakravarty P, Musselman IH et al. Specific thermal ablation of tumor cells using single - walled carbon nanotubes targeted by covalently - coupled monoclonal antibodies. Int. J. Cancer 125(12), 29702977 (2009).

125. Huber DL. Synthesis, Properties, and Applications of Iron Nanoparticles. Small 1(5), 482-501 (2005).

126. Hervault A, Thanh NNTK. Magnetic nanoparticle-based therapeutic agents for thermo-chemotherapy treatment of cancer. Nanoscale doi:10.1039/c4nr03482a (2014).

\section{* Recent in-depth review on magnetic nanoparticle hyperthermia}

127. Simberg D, Park J-H, Karmali PP et al. Differential proteomics analysis of the surface heterogeneity of dextran iron oxide nanoparticles and the implications for their in vivo clearance. Biomaterials 30(23), 3926-3933 (2009).

128. Abdollah MR, Kalber T, Tolner B et al. Prolonging the circulatory retention of SPIONs using dextran sulfate: in vivo tracking achieved by functionalisation with near-infrared dyes. Farad. Discuss. 175(41), (2014). 
129. Baiu DC, Artz NS, Mcelreath MR et al. High specificity targeting and detection of human neuroblastoma using multifunctional anti-GD2 iron-oxide nanoparticles. Nanomedicine 10(19), 2973-2988 (2015).

* Recent study highlighting that modification of the NP surface of the targeting Ab can reduce non-specific uptake and clearance, and that production of Ab-targeted NPs can be upscaled to GMP standards.

130. Dreaden EC, Austin LA, Mackey MA, El-Sayed MA. Size matters: gold nanoparticles in targeted cancer drug delivery. Ther. Deliv. 3(4), 457-478 (2012).

131. Manson J, Kumar D, Meenan BJ, Dixon D. Polyethylene glycol functionalized gold nanoparticles: the influence of capping density on stability in various media. Gold Bull. 44(2), 99-105 (2011).

132. Fabbro C, Ali-Boucetta H, Da Ros T, Kostarelos K, Bianco A, Prato M. Targeting carbon nanotubes against cancer. Chem. Commun. 48(33), 3911-3926 (2012).

133. Kesharwani PK, Mishra V, Jain NK. Validating the anticancer potential of carbon nanotube-based therapeutics through cell line testing. Drug Discov. Today (2015).

134. Mackowiak SA, Schmidt A, Weiss V et al. Targeted drug delivery in cancer cells with red-light photoactivated mesoporous silica nanoparticles. Nano Lett. 13(6), 2576-2583 (2013).

135. Shao K, Singha S, Clemente-Casares X, Tsai S, Yang Y, Santamaria P. Nanoparticle-Based Immunotherapy for Cancer. ACS nano (2014).

* Review on the evolving role of nanoparticles in cancer immunotherapy

136. Steenblock ER, Fadel T, Labowsky M, Pober JS, Fahmy TM. An artificial antigen-presenting cell with paracrine delivery of IL-2 impacts the magnitude and direction of the T cell response. J. Biol. Chem. 286(40), 34883-34892 (2011). 